\title{
Genetic diversity of Schistosoma haematobium parasite IS NOT associated with severity of disease in an endemic area in Sudan
}

\author{
Nagla Gasmelseed ${ }^{1 *}$, Nhashal E Karamino ${ }^{1}$, Mohammed O Abdelwahed ${ }^{1}$, Anas O Hamdoun² \\ and Ahmed E Elmadani
}

\begin{abstract}
Background: Over 650 million people globally are at risk of schistosomiasis infection, while more than 200 million people are infected of which the higher disease rates occur in children. Eighty three students between 6-20 years (mean $12.45 \pm 3.2$ ) from Quran School for boys in Radwan village, Gezira state were recruited to investigate for the relationship between the genetic diversity of Schistosoma haematobium strains and the severity of the disease.

Method: Schistosoma haematobium infection was detected by filtration of urine. Ultrasonography was done on each study subject, while PCR technique was used for genotyping via random amplified polymorphic DNA (RAPD) with A01, A02, A12, Y20 and A13 primers. A01 primer gave three different genotypes (A01-1, A01-2 and A01-3).

Results: About 54.2\% (45/83) were S. haematobium egg positive by urine filtration. On assessment of the upper and lower urinary tract by ultrasound technique, 61.4\% (51/83) were positiveand73.3\% (60/83) samples were PCR positive. No significant difference was found when comparing the three different genotypes with severity of the disease.

Conclusion: This study concludes that no association was found between the different genotypes of S.haemtobium and the severity of the disease. Examination of more samples from different areas to identify any possible differences between the parasites genes and disease severity was recommended.
\end{abstract}

Keywords: S. haematobium, Genetic diversity, Ultrasound, Severity, Gezira State, Sudan

\section{Background}

The genome of Schistosoma is approximately $270 \mathrm{Mbp}$ [1], which is considerably about one tenth the size of the human genome. It is estimated that the S. mansoni genome has a GC content of 34\% [2], with 4-8\% highly repetitive sequence, $32-36 \%$ middle repetitive sequence and $60 \%$ single copy sequence [1]. Numerous highly or moderately repetitive elements have been identified and their occurrence within existing sequence datasets also indicates that the genome contains at least 30\% repetitive sequence [3]. With genetic crossing occurring between adult worms, heterogeneity of an infection may strongly influence development of new variants of the

\footnotetext{
*Correspondence: nag_la@hotmail.com

'Department of Molecular Biology, National Cancer Institute, University of Gezira, Wadmedani, Sudan

Full list of author information is available at the end of the article
}

parasite [4]. Recent studies using randomly amplified polymorphic DNA (RAPDs) markers have found multiple genotype infections by $S$. haematobium in the Planorbidae intermediate host [5,6]. RAPDs mainly segregate as dominant markers with heterozygous and homozygous dominant individuals having the same banding pattern at a locus [6], while homozygous recessive individuals have no band at that locus. Statistical measures taking this limitation into account have been developed in order to derive population parameters describing heterozygosity, gene flow, linkage disequilibrium, and other factors [7]. Randomly amplified polymorphic DNA (RAPD) studies of Schistosoma mansoni infection in naturally infected rodent species revealed even more genetic diversity per infection with as many as 28 specific genotypes per rat [8].

Although few specific primers for polymorphic regions exist, RAPD-polymerase chain reaction (PCR) technology 
has made it possible to conduct population-based studies of schistosomes with little prior sequence information [9]. RAPD primers have been used in several studies to examine the genetic diversity among populations of schistosomes in snails $[10,11]$ and have proved valuable despite the assumptions necessary for their interpretation [12]. They have demonstrated that, with S. haematobium, it is feasible to sample a population of parasites conveniently and arrive at estimates of the frequency of various alleles using RAPD-PCR. The method of schistosome sampling, through single genetic drift, and through limited numbers of infected snails, snail mortality, does play a role, increasing the numbers of snails for haematobium [13]. Knowing the extent of parasite gene flow and the nature of any barriers to such flow will be important in predicting the likely washing spread of drug resistance genes, if they appear [13]. RAPD primers survey a large number of loci throughout the entire genome and have proven useful in characterizing both inter- and intraspecific relationships [14,15]. As very little DNA is required for such analyses, cercarial or miracidial stages of schistosomes can be used as a source of genetic material, thus minimizing selection caused by passaging through unnatural hosts $[13,16]$.

Distribution of S.haematobium in Sudan in several irrigation schemes have been constructed e.g. Gezira, Rahad Agriculture Scheme, Ginaid, AL Gerba, Kenana and other sugar cane schemes [17], also found in small part of Blue Nile, southern of Sudan [18]. Little is known about the extent of genetic diversity of $S$. haematobium within its definitive host, humans. Understanding the genetic structuring of populations at each stage of the life cycle is essential to account for the creation of diversity and its maintenance in natural populations of parasites [19]. Genetic variability among parasite populations is an important factor in their potential for producing harmful effects on the human populations. Since damage from schistosome infections is so closely linked to the immune reaction to parasite eggs deposited in tissue, diversity of this infection may play an important role in development of pathology with heterogeneous versus homogeneous infections resulting in different clinical outcomes. Genetic differences may also lead to some strains being innately more immunogenic or fecund than others [20]. The aim of this study was to identify if there is any relationship between the genetic diversity of S.haematobium and pathology of the disease in school children in Gezira State, Sudan.

\section{Methods}

\section{Study area}

This study was conducted in Roudwan village, located in the south west of Wadmedeni city. This village is a part of Gezira irrigation scheme and surrounded by canals from the south and east. There is only one small health center and no school as most of the children study in Khalwa (Quranic schools). No safe water source is available, and the main source of water is from canals.

Quranic School (Khalwa) was selected for this study and the students came from different regions of Gezira state and other states of Sudan such as (Blue Nile state, White Nile state, Sennar, Gadarif). They stay up to 15 years to study the Quran. All the students were at risk of infection of schistosomiasis due to the daily exposure to the infection by swimming and daily activities in canal water. Eighty three students aged 6-17 years old were recruited from Hilt Radowan (Khalwa).

\section{Urine filtration technique}

Urine sample were collected from each students and $10 \mathrm{ml}$ examined by filtration method [21]. S.haematobium eggs were detected and egg count recorded as number of egg/10 $\mathrm{ml}$. The remaining urine was centrifuged and the deposit kept at $-80^{\circ} \mathrm{C}$ as preparation for DNA extraction. The students were weighted and all positives for S. haematobium infections were treated with Praziquantel.

\section{Ultrasound examination}

Ultrasonographic examination was done by expert radiologist on each student. Transabdominal ultrasonographic examination of the urinary tract was performed by Aloka (5100) with a $3.5 \mathrm{MHz}$ convex probe and Shimadzu with convex probe 2-5 and 5-10 MHz on all the study subjects after adequate filling of the bladder. Urinary tract and kidneys were examined according to WHO standards [22]. The bladder was evaluated using a $3.5 \mathrm{MHz}$ sector scan in three directions. Bladder wall thickness was measured, and mucosal irregularities, masses or pseudopolyps were classified as proposed by the WHO workshop [22]. Irregularities of the bladder wall or thickening were considered pathological in the case of more than $0.5 \mathrm{~cm}$ in thickness. Ureter dilation was evaluated in the retrovesical region and if indicated this examination was repeated after micturition to exclude vesico-ureteral reflux. The severity of S.haematobium divided according to the size of bladder wall thickening irregularity, calcification, nodularity, dilatation and ureter thickness, nodularity, dilatation, calcification and kidney dilatation, and echogencity. Classification of severity was done by ultrasonographicas normal or abnormal finding in upper and lower urinary tract.

\section{Genotyping of S. haematobium DNA using random amplified PCR reaction (RAPD)}

DNA extraction was done for all collected samples using QIAamp DNA Mini kit (Germany). Genotyping of S. haematobium DNA using Random Amplified PCR Reaction (RAPD) test the amplification conditions were based on the original method described by Williams et al (1990). In this study five primers were used for genotyping 
of S. haematobium strain (A01, 5'-CAGGCCCTTC-3'; A02, 5' -TGCCGAGCTG-3';A12, 5' -TCGGCGATAG-3'; A13, 5'-CAGCACCCAC-3';Y20,5'-AGCCGTGGAA-3';), primers were selected according to Shiff et al (2000). Amplification reaction was carried out in a final volume of $25 \mu \mathrm{l}$ and the PCR product determined on $4 \%$ polyacrylamide by electrophoresis.

\section{Ethical approval}

Ethical clearance was obtained from National Cancer Institute Research Ethical committee NCI-REC University of Gezira. Prior to conducting the study, aims and all information about the study was explained to community during meetings. Written consent was obtained from the local leaders. All infected subjects were treated immediately after diagnosis.

\section{Statistical analysis}

Data was analyzed using SPSS version 16 statistical package. Descriptive, correlation and chi square analysis done in this study.

\section{Results}

All of the study subjects were males; the mean age was $12.45 \pm 3.2$ with age range between $6-20$ years. The majority of age groups were between 9-11years, $36.1 \%$ (30) followed by $12-14$ years $26.5 \%$ (22) as shown in Figure 1. About $54.2 \%(45)$ of the students were positive to S.haematobium by filtration. The stratification of the age range showed that the high positive frequency was $18 \%(15)$ in the age range (9-11 years), as in Figure 2.

The intensity of infection was classified as egg count $<100$ eggs recorded as low level infection and between 101-199 eggs as moderate and $>200$ eggs as high intensity of infection [23]. Forty three out of 45 (75.5\%) had a low intensity of infection while only $9.0 \%$ (4) had a high intensity (Figure 3).

\section{Detection of S.haematobium by Ultrasound}

Eighty three of the Khalwas' students were diagnosed by ultrasound. The diagnosis included upper urinary tract (Kidneys and ureters) and lower urinary tract (urinary bladder). About 85\% (51) of study subjects had pathological changes. Those with abnormalities were 85.9\% (49); abnormal wall thickness 56.8\% (29) multiple nodularities and 3.9\% (2) one polyp as shown in Figure 4A, and1.9\% (1) wall bladder calcifications, $11.7 \%$ (22) abnormal ureteric thickness (Figure 4B) and 3.9\%(2) echogenic particles (Table 1).

\section{Molecular genotyping of S.haematobium strain}

PCR was done for all urine samples using RAPD test 72.3\% (60) study subjects had a PCR product for A01 primer, while no product was detected for the other primers (A02, A12, A13, Y20). A01 primer showed three different genotypes mentioned as genotype $(1,2$, and 3$)$ in polyacrylamide gel using 100 bp DNA marker polymorphic band in marker 700, 800, 900, 1100 bp (Figure 5).

\section{S.haematobium infection severity and the genotypes}

72.3\% (60) were positive by PCR; 80\% (48) were genotyped A01- genotype 1, 15\% (9) were genotype A01-genotype2 and 5\% (3) were genotype A03-3. Correlation between severity and genotype of S.haematobium, genotype A01 (genotype1) recorded;33.3\% (16) study subjects were mild, $20.8 \%$ (10) had moderate severity and 20.8\% (10) had severe feature of the disease. Genotype A01-2 was recorded $44.4 \%$ (4) moderate and $22.3 \%$ (2) were severe.

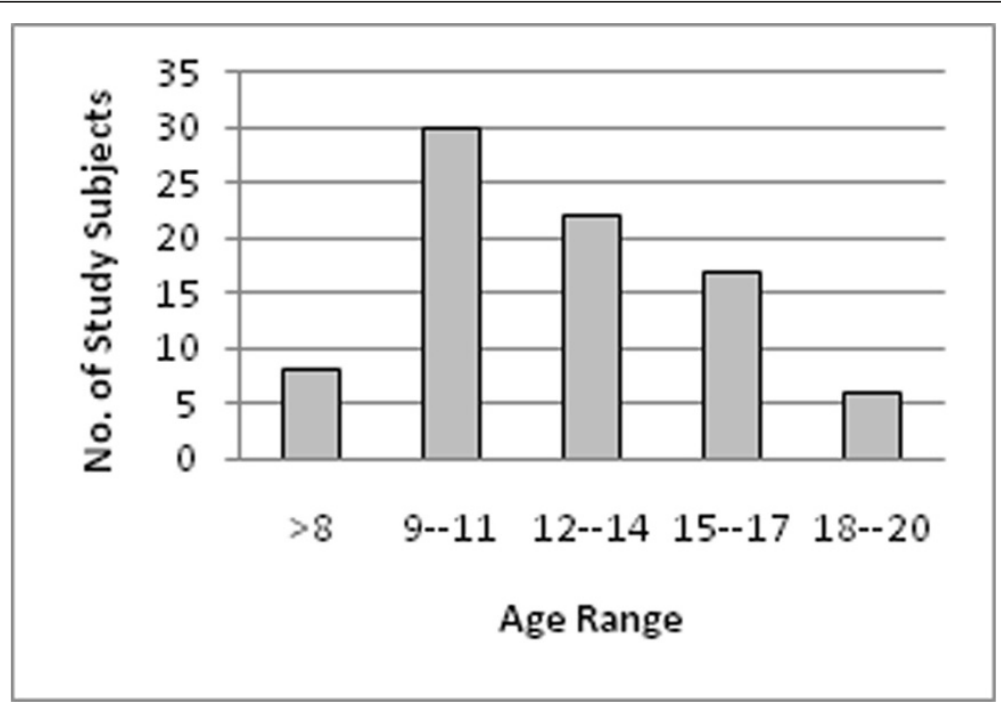

Figure 1 Distribution of the study subjects by age range, $\mathrm{N}=83$. 


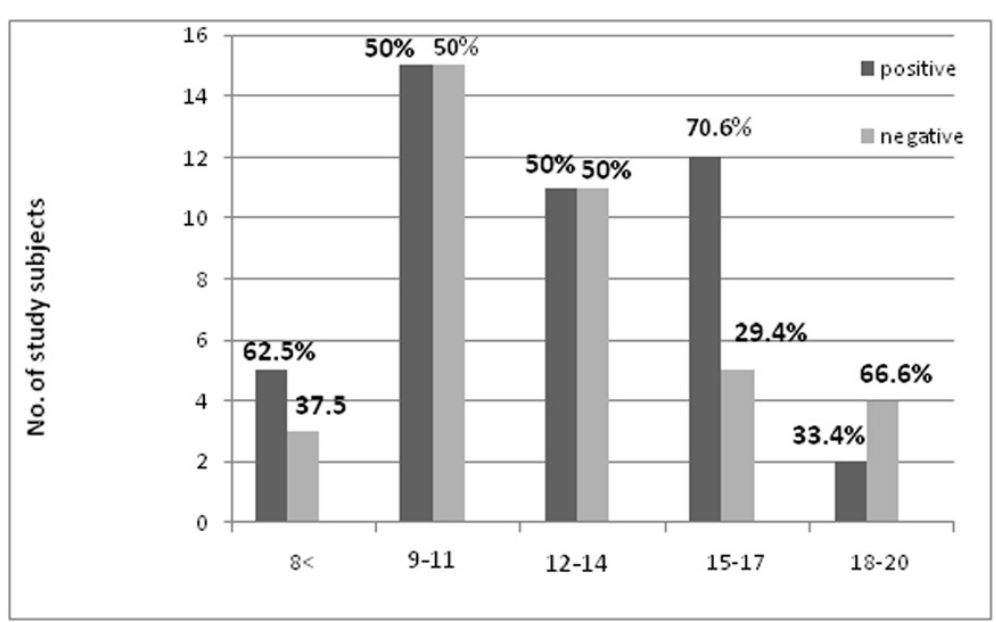

Figure 2 Shows the results of study subjects age groups by filtration technique, $\mathrm{N}=45$.

There is no significant correlation between Severity of S.haematobium and the genotypes Pearson Chi-Square $=24$, P- Value $=0.004$ (Table 2).

Forty five study subjects were positive by PCR and filtration; 87\% (39) were genotype A01 - 1, 9\% (4) were genotype A02-2 and 5\% (2) were genotype A03-3. Correlation between infection severity and genotype of S.haematobium, genotype A01 (type1) recorded; 25.6\% (10) normal and $38.4 \%$ (15) mild, $18 \%$ (7) had moderate infection severity and 18\% (7) had severe clinical feature. Genotype A01-2 had 50\% (2) normal and 25\% (1) were severe, while $25 \%$ (1) were moderate. There is no significant correlation between Severity of S.haematobium and the genotypes Pearson Chi-Square $=4, \mathrm{p}=0.6$, (Table 3).

Fifteen study subjects were positive by PCR and negative by filtration; 9/15 was genotype A01- 1 , while 5were genotype A02-2 and 1were genotype A03-3. Correlation between infection severity and genotype of S. haematobium, genotype A01 (type1) recorded;11.1\% (1) normal and 22.3\% (2) mild, 33.3\% (3) had moderate infection severity and 33.3\% (3) had severe clinical feature. Genotype A01-2 had $60 \%$ (3) moderate and 20\% (1) had severe infection, while $20 \%$ (1) were normal. There is no significant correlation between infection severity of S.haematobium and the genotypes Pearson Chi-Square $=6, p=0.3$ (Table 4).

\section{Discussion}

Schistosomiasis affects approximately 200 million people, mainly in rural areas of developing countries, with an estimated 79 million people at risk of the disease [24]. Both S. haematobiumand S. mansoni are present in Sudan. Schistosomiasis is found in many different areas in Sudan

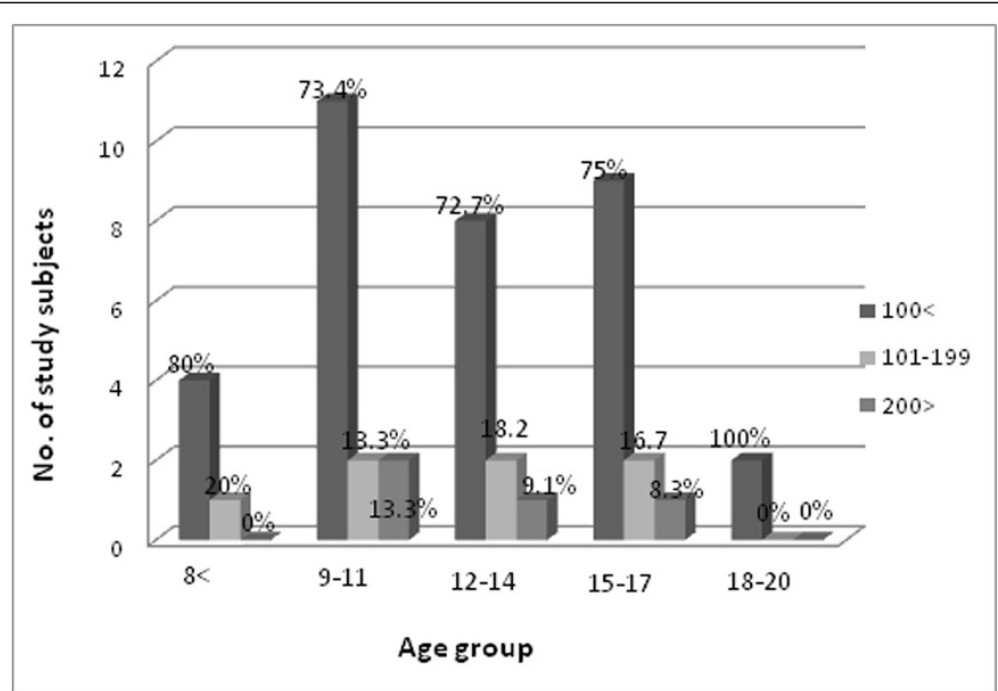

Figure 3 Shows result of S.haematobium egg count by filtration technique, of 45 study subjects. 

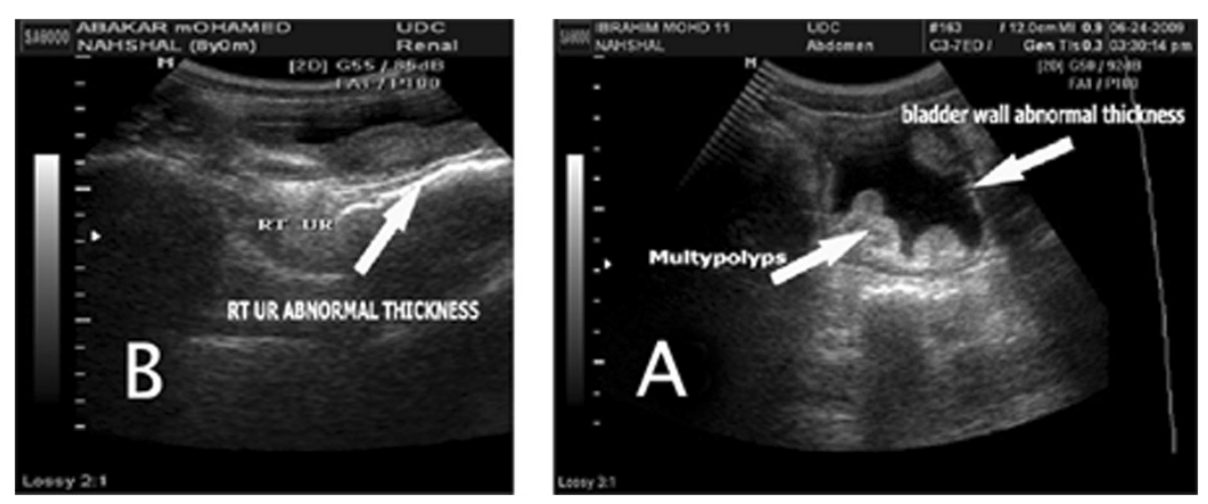

Figure 4 Shows Ultrasound Image. A: shows thickness on wall of bladder, polyps and calcification B: shows thickness of ureter $6 \mathrm{~mm}$ and Ultrasonographic examination was done by experienced radiologist.

especially in Gezira, Rahad, Kenana and other irrigation schemes $[25,26]$. The dynamics of the transmission are necessarily complicated and subject to considerable variation due to many factors influencing the common environment, the behavioural patterns of the definitive host and the bionomic of the intermediate host.

This study was carried out in Radwan village in Gezira state, Sudan. The village is surrounded by canals without sufficient safe water supply. S. haematobium started increasing in the last decade after control of S.mansoni in Gezira area [17]. Schistosomiasis affects males more than females (unpublished report 2011), since males are more exposed to the water supply than females (culturally).

In this study $51 \%$ of study subjects were found to have abnormal pathological conditions including; 85.9\% (49) abnormal wall thickness $56.8 \%(29)$ multiple nodularity and $3.9 \%$ (2) one polyps and $1.9 \%$ (1) wall bladder calcifications. When compared to a similar study from Mali [27] more irregular bladder wall were the most frequently diagnosed abnormality in $3.4 \%$ of children. Study from Nigeria [28] reported 71\% abnormal pathological conditions; abnormal wall thickness $(55.8 \%)$ while in our study $56.8 \%$, irregular bladder wall $(27.9 \%)$, masses $(23.3 \%)$, pseudo polyps $2(4.7 \%)$ compare with $5.8 \%$ in this study. These studies reported similar findings that most abnormal urinary bladder wall recorded in children below 15 years old. In this study there was no correlation between ultrasound abnormal urinary tract findings and intensity of infection $(P=0.21)$. This is contrary to the study from Nigeria [28] that reported abnormal pathology slightly more common in the study subjects with heavy infection than those with light infection.

Another study conducted in southern Nigeria identified about $6.7 \%$ and $1.7 \%$ of the patients had the right pelvis and left pelvis of their kidney moderately dilated, respectively [29]; in contrast to this study where no kidney abnormalities were found probably due to duration of infection in the study participants.

Schistosomiasis diagnosis by PCR results recorded $72.3 \%$ (60) while schistosomiasis diagnosis by filtration methodsrevealed $54.2 \%$ (45), this may be due to presence of a small number of eggs that are difficult to diagnose by the microscope. Many studies confirmed the sensitivity of PCR to detect egg of S.haematobium in urine to be more sensitive than filtration technique. A study performed in Ghana using PCR methods for diagnosis reported sensitivity $100 \%$ and specificity at $89 \%$ [30], in contrast using PCR in this study, sensitivity was $100 \%$ and specificity was $60.5 \%$. It is well known that sensitivity of PCR to diagnosis S.haematobium is more sensitive than filtration; this was indicated by 15 study subject in this study found negative by filtration while

Table 1 Ultrasound finding of the study subjects by age range

\begin{tabular}{|c|c|c|c|c|c|c|c|}
\hline \multirow[t]{2}{*}{ Age range } & \multirow[t]{2}{*}{ Total (\%) } & \multirow[t]{2}{*}{ Thickness (\%) } & \multicolumn{2}{|l|}{ Bladder mass } & \multirow{2}{*}{$\begin{array}{l}\text { Bladder wall } \\
\text { Calcification (\%) }\end{array}$} & \multirow[t]{2}{*}{ Ureter thickness (\%) } & \multirow[t]{2}{*}{ Echogncity (\%) } \\
\hline & & & One polyp (\%) & Multiple (\%) & & & \\
\hline$>8$ & $5(9.8)$ & $5(10.2)$ & $1(50)$ & $3(10.3)$ & 0 & 0 & 0 \\
\hline $9-11$ & $21(41.2)$ & $20(40.8)$ & 0 & $14(48.3)$ & 0 & $7(31.8)$ & 0 \\
\hline $12-14$ & $16(31.4)$ & 15 (30.6) & $1(50)$ & $9(31.0)$ & $1(100)$ & $8(36.4)$ & 0 \\
\hline $15-17$ & $7(13.7)$ & $7(14.3)$ & 0 & $2(6,9)$ & 0 & $5(22.7)$ & $1(50)$ \\
\hline $18-20$ & $2(3.9)$ & $2(4.1)$ & 0 & $1(3.4)$ & 0 & $2(9.1)$ & $1(50)$ \\
\hline Total (\%) & $51(100 \%)$ & 49 (100) & $2(100)$ & $29(100)$ & $1(100)$ & $22(100)$ & $2(100)$ \\
\hline
\end{tabular}




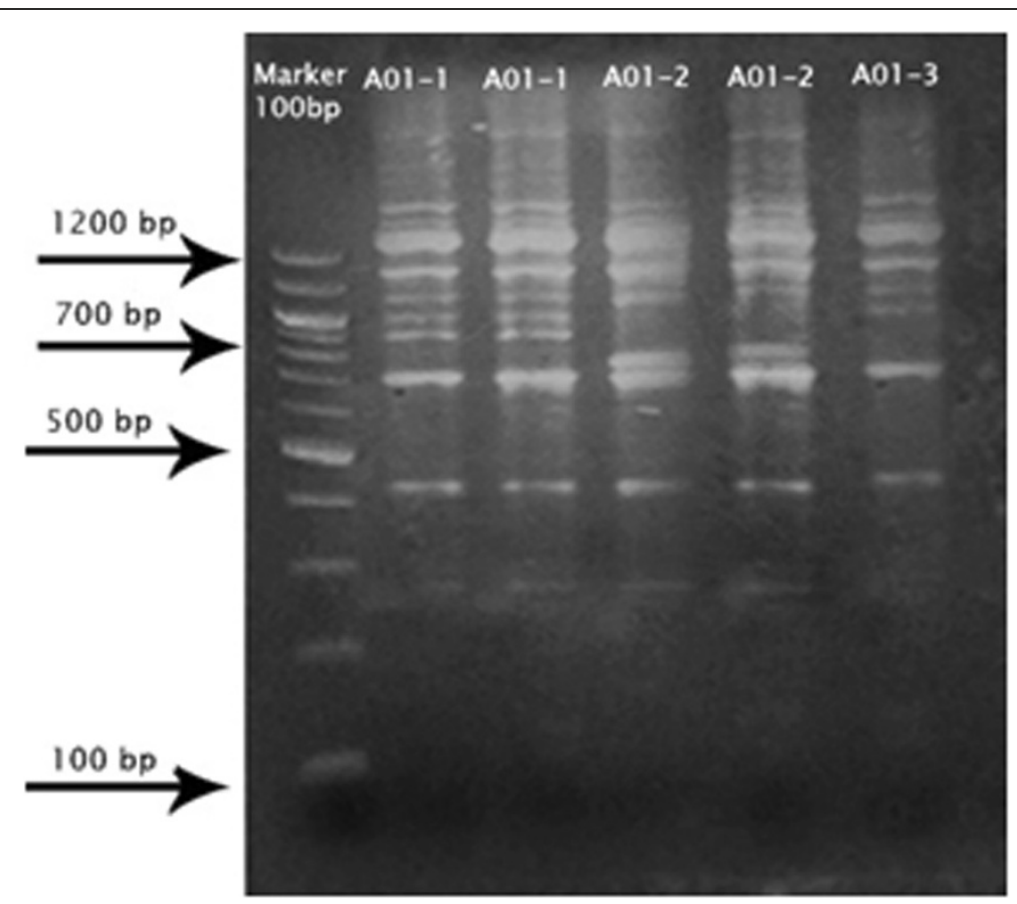

Figure 5 Shows S.haematobium genotypes for A01 primer in polyacrylamide gel.

they were positive by PCR. But the study from northern Senegal showed significant correlation with microscopic egg counts both for S. mansoni in stool and S. haematobium in urine. They found that Schistosoma detection rate of PCR (84.1\%) was similar to that of microscopy performed on duplicate stool samples (79.5\%) [31], that may be due to high intensity of infection that made the sensitivity of filtration similar to PCR.

In this study PCR was done by Using RAPD test 72.3\% (60) study subjects had a PCR product for A01 primer, A01 primer showed different three genotypes (1, 2, and 3) $80 \%$ (48) were genotype A01-1 while 9/60 (15\%) genotype A01 - 2 and 5\% (3) genotype A01-3, in polyacrylamide gel. Study done by [13] RAPD fragments of an inbred Egyptian strain of S. haematobium generated by primers G17 and A02, using miracidial isolate from a particular host. Differences in alleles were recorded among the 37 variable bands. In this study, only three variable bands were

Table 2 Shows association between severities and genotypes of S.haematobium, $N=60$

\begin{tabular}{llllll}
\hline \multirow{2}{*}{$\begin{array}{l}\text { Genotype } \\
\text { A 01 }\end{array}$} & \begin{tabular}{l} 
Sormal \\
\cline { 2 - 5 }
\end{tabular} & $\begin{array}{l}\text { Mild } \\
\text { (\%) }\end{array}$ & $\begin{array}{l}\text { Moderate } \\
(\%)\end{array}$ & $\begin{array}{l}\text { Severe } \\
(\%)\end{array}$ & \\
\hline Genotype 1 & $11(73.3)$ & $17(94.4)$ & $10(71.4)$ & $10(76.9)$ & $48(80)$ \\
Genotype 2 & $3(18.7)$ & $0(00)$ & $4(28.6)$ & $2(15.4)$ & $9(15)$ \\
Genotype 3 & $1(6.7)$ & $1(5.6)$ & $0(00)$ & $1(7.7)$ & $3(5)$ \\
Total & $15(100)$ & $18(100)$ & $14(100)$ & $13(100)$ & $60(100)$ \\
\hline
\end{tabular}

recorded, and polymorphic region was between 700 and $1100 \mathrm{bp}$. The small number of variation alleles in this study refer to the samples collection from children infected with schistosomiasis which transmitted to them from the same study area, while [13] study samples were collected from infected students coming from different regions infected with Schistosoma, this can increase the chances of finding more different polymorphic.

RAPD primers have been used in several studies to examine the genetic diversity among populations of schistosomes in snails [5]. Studies done by [5] at different sites in Bamako, on cercariae isolated from different snails and 47 different genotypes were recorded from 414 schistosome individuals. Ten primers (A01, A02, A10, A13, A19, G09, G11, G17, G19, G18) were used but only three primers were detected (A01, A10, G19), In this study 5 primers (A01, A02, A12, Y20 and A13) were used but only one primer was detected A01,the results were consistent

Table 3 Shows association between severity and positive study subject by filtration method and positive by PCR, N $=45$

\begin{tabular}{llllll}
\hline & \multicolumn{2}{l}{ Severity of the disease } & \multicolumn{2}{l}{ Total (\%) } \\
\cline { 2 - 6 } Genotype A 01 & Normal (\%) & Mild (\%) & Moderate & Severe & \\
\hline Genotype 1 & $10(83.3)$ & $15(93.8)$ & $7(87.5)$ & $7(77.8)$ & $39(87)$ \\
Genotype 2 & $2(16.7)$ & 0 & $1(12.5)$ & $1(11.1)$ & $4(9)$ \\
Genotype 3 & $0(00)$ & $1(6.2)$ & 0 & $1(11.1)$ & $2(5)$ \\
Total & $12(100)$ & $16(100)$ & $8(100)$ & $9(100)$ & $45(100)$ \\
\hline
\end{tabular}


Table 4 Shows association between severity and negative study subject by filtration method and positive by $\mathrm{PCR}, \mathrm{N}=15$

\begin{tabular}{llllll}
\hline \multirow{2}{*}{$\begin{array}{l}\text { Genotype } \\
\text { A 01 }\end{array}$} & \multicolumn{3}{l}{ Severity of the disease } & Total (\%) \\
\cline { 2 - 5 } & $\begin{array}{l}\text { Normal } \\
\text { (\%) }\end{array}$ & $\begin{array}{l}\text { Mild } \\
\mathbf{( \% )}\end{array}$ & $\begin{array}{l}\text { Moderate } \\
\text { (\%) }\end{array}$ & $\begin{array}{l}\text { Severe } \\
(\%)\end{array}$ & \\
\hline Genotype 1 & $1(33.3)$ & $2(100)$ & $3(50)$ & $3(75)$ & $9(60)$ \\
Genotype 2 & $1(33.3)$ & $0(00)$ & $3(50)$ & $1(25)$ & $5(33)$ \\
Genotype 3 & $1(33.3)$ & $0(00)$ & $0(00)$ & $0(00)$ & $1(6.4)$ \\
Total & $3(100)$ & $2(100)$ & $6(100)$ & $4(100)$ & $15(100)$ \\
\hline
\end{tabular}

with the study conducted by [5] with respect to genotype A01, where it was detected in the two studies, while genotype A02 and A13were used but did not give any results. Primer A01 revealed two polymorphic bands in marker $1100 \mathrm{bp}$, while in our study other variability in marker between 700 and 900 bp was noted. That means the findings show more different genotype when more than five primers are used or by increasing the study population that increases the chances of finding other genetic differences. In this study $46 \%$ of the subjects were positive by PCR with normal pathology by ultrasound. Most of these subjects belong to genotype A01, that may refer that the genotype is not aggressive enough to cause severe disease.

Morbidity manifestations have great role in diagnosis S.haematobium and genetic differences may lead to some strains being innately more immunogenic or fecund than others, these differences may play important role in severity features. There are few studies that found the relation between severity and genetic diversity [20]. In this study the association between the severity and genotypes was not found compared with a study from Zimbabwe that used ultrasonography to characterize the extent of urinary tract pathology of infected children, and random genetic markers to examine the relationship between genetic diversity of S. haematobium and clinical outcome. They found that parasite heterogeneity did not differ; allelic frequencies at eight loci differed significantly between the mild and severe groups. Parasite isolates were analyzed further using a modified cluster analysis that segregated the population into 13 clusters of associated genotypes. Three clusters were significantly over-represented in children with severe lesions. Although preliminary parasite genetic associations may be important in clinical outcome ([20]. In this study the genotype A01 type one was recorded as highest in severe $16.6 \%$ while $16.7 \%$ also were moderate, A01 type 2 was recorded 3.4\% study sample severe and $6.7 \%$ moderate. There was no association between morbidity and different genotype as reported in a study from Zimbabwe. This may be due to $S$. haematobium infections differ under controlled circumstances, where factors such as exposure to parasites, infection intensity, type of parasite strains.

\section{Conclusion}

Molecular characterization on S.haematobium proved that primer A01 with three different genotypes (polymorphic band between 700 and $1100 \mathrm{bp}$ ), is the most prevalent strain in study area. Difference in genotypes of S.haematobium may play a major role in severity features. However, molecular characterization of strain is needed to identify the type of strain in the area which may facilitate prevention and treatment. More samples from different parts of the state will be collected for future molecular study of the strains.

\section{Competing interests}

The authors declare that they have no competing interests.

\section{Authors' contributions}

NG, PhD Molecular Biology (writing the manuscript and supervising all the work) NEK (collects the samples and doing the lab work). MOA (supervising the lab work). $\mathrm{AOH} ; \mathrm{MD}$ Radiology (doing ultrasonography) and AEE; MD Radiology (doing ultrasonography). All authors read and approved the final manuscript.

\section{Acknowledgement}

Thanks for the Khalwas' school member for their great help and support. would like to express my thanks to the Ministry of Health Gezira State for providing treatment.

\section{Author details}

${ }^{1}$ Department of Molecular Biology, National Cancer Institute, University of Gezira, Wadmedani, Sudan. ${ }^{2}$ Department of Medical Imaging, National Cancer Institute, University of Gezira, Wadmedani, Sudan.

Received: 29 April 2014 Accepted: 12 August 2014

Published: 27 August 2014

\section{References}

1. Simpson AJ, Sher A, McCutchan TF: The genome of Schistosoma mansoni: isolation of DNA, its size, bases and repetitive sequences. Mol Biochem Parasitol 1982, 6(2):125-137.

2. Hillyer GV, Lewert RM: Studies on renal pathology in hamsters infected with Schistosoma mansoni and S. japonicum. Am J Trop Med Hyg 1974, 23(3):404-411.

3. Le Paslier MC, Pierce RJ, Merlin F, Hirai H, Wu W, Williams DL, Johnston D, LoVerde PT, Le Paslier D: Construction and characterization of a Schistosoma mansoni bacterial artificial chromosome library. Genomics 2000, 65(2):87-94.

4. Brouwer KC, Ndhlovu P, Munatsi A, Shiff CJ: Genetic diversity of a population of Schistosoma haematobium derived from schoolchildren in east central Zimbabwe. J Parasitol 2001, 87(4):762-769.

5. Dabo A, Durand P, Morand S, Diakite M, Langand J, Imbert-Establet D, Doumbo $\mathrm{O}$, Jourdane J: Distribution and genetic diversity of Schistosoma haematobium within its bulinid intermediate hosts in Mali. Acta Trop 1997, 66(1):15-26.

6. Davies CM, Webster JP, Kruger O, Munatsi A, Ndamba J, Woolhouse ME: Hostparasite population genetics: a cross-sectional comparison of Bulinus globosus and Schistosoma haematobium. Parasitology 1999, 119(Pt 3):295-302.

7. Kuhner MKYJ, Felsenstein J: Estimating effective population size and mutation rate from sequence data using Metropolis-Hastings sampling. Genetics 1995, 140(4):1421-1430.

8. Barral V, Morand S, Pointier JP, Theron A: Distribution of schistosome genetic diversity within naturally infected Rattus rattus detected by RAPD markers. Parasitology 1996, 113(Pt 6):511-517.

9. Welsh J, McClelland M: Fingerprinting genomes using PCR with arbitrary primers. Nucleic Acids Res 1990, 18(24):7213-7218.

10. Minchella DJ, Lewis FA, Sollenberger KM, Williams JA: Genetic diversity of Schistosoma mansoni: quantifying strain heterogeneity using a polymorphic DNA element. Mol Biochem Parasitol 1994, 68(2):307-313.

11. Sire C, Durand P, Pointier JP, Theron A: Genetic diversity and recruitment pattern of Schistosoma mansoni in a Biomphalaria glabrata snail population: a field study using random-amplified polymorphic DNA markers. J Parasitol 1999, 85(3):436-441.

12. Lynch M, Milligan BG: Analysis of population genetic structure with RAPD markers. Mol Ecol 1994, 3(2):91-99. 
13. Shiff C, Brouwer KC, Clow L: Schistosoma haematobium: population genetics of $\mathrm{S}$. haematobium by direct measurement of parasite diversity using RAPD-PCR. Exp Parasitol 2000, 96(1):47-51.

14. Barral V, This P, Imbert-Establet D, Combes C, Delseny M: Genetic variability and evolution of the Schistosoma genome analysed by using random amplified polymorphic DNA markers. Mol Biochem Parasitol 1993, 59(2):211-221.

15. Dias Neto EDSC, Rollinson D, Katz N, Pena SD, Simpson AJ: The random amplification of polymorphic DNA allows the identification of strains and species of schistosome. Mol Biochem Parasitol 1993, 57(1):83-88.

16. LoVerde PT, DeWald J, Minchella DJ: Further studies of genetic variation in Schistosoma mansoni. J Parasitol 1985, 71(6):732-734.

17. Gasmelseed N, Kurmino N, Ahmed HM: The effect of the socio-economic factors on transmission of parasitic diseases in Gezira State Central Sudan. 11th International Congress of Parasitology ICOPA XI, Glasgow United Kingdoum 2006:23-27.

18. Deganello RCM, Beltramello C, Duncan O, Oyugi V, Montresor A: Schistosoma hematobium and S. mansoni among children, Southern Sudan. Emerg Infect Dis 2007, 13(10):1504-1506.

19. Curtis J, Minchella DJ: Schistosome population genetic structure: when clumping worms is not just splitting hairs. Parasitol Today 2000, 16(2):68-71.

20. Brouwer KC, Ndhlovu PD, Wagatsuma Y, Munatsi A, Shiff CJ: Urinary tract pathology attributed to Schistosoma haematobium: does parasite genetics play a role? Am J Trop Med Hyg 2003, 68(4):456-462.

21. French MDRD, Basanez MG, Mgeni AF, Khamis IS, Stothard JR: School-based control of urinary schistosomiasis on Zanzibar, Tanzania: monitoring micro-haematuria with reagent strips as a rapid urological assessment. J Pediatr Urol 2007, 3(5):364-368.

22. Hatz C, Murakami H, Jenkins JM: A review of the literature on the use of ultrasonography in schistosomiasis with special reference to its use in field studies. 3. Schistosoma japonicum. Acta Trop 1992, 51(1):29-36.

23. Mqoqi NP, Appleton CC, Dye AH: Prevalence and intensity of Schistosoma haematobium urinary schistosomiasis in the Port St Johns district. S Afr Med J 1996, 86(1):76-80.

24. Steinmann KJ, Bos R, Tanner M, Utzinger J: Schistosomiasis and water resources development: systematic review, meta-analysis, and estimates of people at risk. Lancet Infect Dis 2006, 6(7):411-425.

25. Eltoum IA, Sulaiman S, Ismail BM, Ali MM, Elfatih M, Homeida MM: Evaluation of haematuria as an indirect screening test for schistosomiasis haematobium: a population-based study in the White Nile province. Sudan Acta Trop 1992, 51(2):151-157.

26. Ahmed ES, Daffalla A, Christensen NO, Madsen H: Patterns of infection and transmission of human schistosomiasis mansoni and schistosomiasis haematobium in White Nile Province. Sudan Ann Trop Med Parasitol 1996, 90(2):173-180

27. Keita AD, Sangho H, Sacko M, Diarra Z, Simaga SY, Traore I: Prevalence of schistomasiasis lesions detected by ultrasonography in children in Molodo. Mali. Gastroenterol Clin Biol 2005, 29(6-7):652-655.

28. Nmorsi OP, Ukwandu NC, Ogoinja S, Blackie HO, Odike MA: Urinary tract pathology in Schistosoma haematobium infected rural Nigerians. Southeast Asian J Trop Med Public Health 2007, 38(1):32-37.

29. Ekwunife CA, Okafor FC, Nwaorgu OC: Ultrasonographic screening of urinary schistosomiasis infected patients in Agulu community, Anambra state, southeast Nigeria. Int Arch Med 2009, 2(1):34.

30. Obeng BB, Aryeetey YA, de Dood CJ, Amoah AS, Larbi IA, Deelder AM, Yazdanbakhsh M, Hartgers FC, Boakye DA, Verweij JJ, van Dam GJ, van Lieshout L: Application of a circulating-cathodic-antigen (CCA) strip test and real-time PCR, in comparison with microscopy, for the detection of Schistosoma haematobium in urine samples from Ghana. Ann Trop Med Parasitol 2008, 102(7):625-633.

31. Hove RJ, Verweij JJ, Vereecken K, Polman K, Dieye L, van Lieshout L: Multiplex real-time PCR for the detection and quantification of Schistosoma mansoni and $\mathrm{S}$. haematobium infection in stool samples collected in northern Senegal. Trans R Soc Trop Med Hyg 2008, 102(2):179-185.

doi:10.1186/1471-2334-14-469

Cite this article as: Gasmelseed et al:: Genetic diversity of Schistosoma haematobium parasite IS NOT associated with severity of disease in an endemic area in Sudan. BMC Infectious Diseases 2014 14:469.

\section{Submit your next manuscript to BioMed Central and take full advantage of:}

- Convenient online submission

- Thorough peer review

- No space constraints or color figure charges

- Immediate publication on acceptance

- Inclusion in PubMed, CAS, Scopus and Google Scholar

- Research which is freely available for redistribution 